Check for updates

Cite this: RSC Adv., 2019, 9, 29676

\title{
Effects of polyols on the quality characteristics of sucrose-free milk chocolate produced in a ball mill
}

\author{
Aziz Homayouni Rad, ${ }^{\text {ab }}$ Haniyeh Rasouli Pirouzian, (D) *a Nevzat Konar, ${ }^{c}$ \\ Omer Said Toker $^{\mathrm{d}}$ and Derya Genc Polat ${ }^{\mathrm{e}}$
}

Sucrose-free milk chocolates containing different types of bulk (isomalt, xylitol and maltitol) and high intensity (Stevia) sweeteners were produced by using a ball mill. The main quality characteristics of the formulated chocolates were evaluated and compared with those of the conventional sample containing sucrose. The Casson model was the best fitting model for the rheological data. Casson viscosity and Casson yield stress were significantly affected by the type of bulking agent in chocolates formulated with xylitol $(p<0.05)$. However xylitol notably improved the overall acceptability according to the sensory analysis results. Chocolates containing the sucrose replacers demonstrated lower $T_{\text {onset }}$ values and higher enthalpy than the control sample. Sucrose-free chocolates illustrated a higher degree of particle agglomeration. Bulk sweeteners meanwhile seem to have high potential for milk chocolate production with low calorie values by using the ball mill technique. Industrial applications: the production of sucrose-free chocolates with conventional methods requires a lot of time and energy. Recently, using alternative methods for chocolate production has been raising interest in many small industries. This study proposed a ball mill method for the preparation of sucrose-free milk chocolates with physiochemical properties almost ranging in the standard limit defined for chocolate. Although using the ball mill method presents a more cost-effective technique for chocolate production and provides shorter processing times for small chocolate industries, it seems to be less efficient in evaporating moisture than the conventional processing. Challenges are still ahead for upgrading this alternative technique to be efficient in evaporating more moisture during operation ending in a high quality product.

\author{
Received 14th June 2019 \\ Accepted 6th September 2019 \\ DOI: $10.1039 / c 9 r a 04486 h$ \\ rsc.li/rsc-advances
}

\section{Introduction}

Moderate consumption of chocolate may help to reduce serious illnesses such as cardiovascular diseases ${ }^{1}$ and cancer $^{2}$ because this product provides the body with minerals ${ }^{3}$ vitamins and especially antioxidants. ${ }^{4}$ But, the high content of sucrose in chocolate can lead to diabetes, ${ }^{5}$ obesity, and heart disease which negatively affect quality of life. A number of manufacturers have offered low-sugar chocolates that are the same in taste, consistency, sweetness and texture. ${ }^{4}$ Although sucrosefree chocolates are healthier, however, the main quality attributes of the product and the side-effects (e.g. laxative) of sucrose

\footnotetext{
${ }^{a}$ Department of Food Science and Technology, Faculty of Nutrition and Food Sciences, Tabriz University of Medical Sciences, Golgasht Avenue, Tabriz, 5165665931, East Azerbaijan Province, Iran.E-mail: rasoulipirouzian@tbzmed.ac.ir; rasuly_h@yahoo. com; Fax: +984133392772; Tel: +9841333866918

${ }^{b}$ Nutrition Research Center, Faculty of Nutrition, Tabriz University of Medical Sciences, Tabriz, Iran

${ }^{c}$ Siirt University, Faculty of Engineering, Department of Food Engineering, 56100, Siirt, Turkey

${ }^{d}$ Yildiz Technical University, Chemical and Metallurgical Engineering Faculty, Food Engineering Department, Istanbul, Turkey

${ }^{e}$ Tayas Food, R\&D Center, Gebze, Kocaeli, Turkey
}

alternatives $^{\mathbf{6}}$ should be considered during re-formulation studies.

Polyols are ideal sucrose substitutes to produce sucrose-free chocolates because they have high bulking capacity, sweetening strength and maintenance the full chocolate flavor. ${ }^{7}$ These ingredients contain fewer calories (nearly $\left.2.4 \mathrm{kcal} \mathrm{g}^{-1}\right)^{8}$ and also induce a very low glycemic effect. ${ }^{9}$ Likewise they can not be dissociated by plaque bacteria and therefore are tooth-friendly. ${ }^{6}$

The physicochemical effects of isomalt, xylitol and maltitol on milk chocolate were investigated among the polyols. The low hygroscopicity and high temperature stability of isomalt (LM) prevents the moisture absorption and agglomeration during production process, respectively. ${ }^{4}$ The extensive use of maltitol in sucrose-free chocolate production is relied on its organoleptic and technological attributes that allow the standard conching temperature to be used. ${ }^{10}$ Xylitol is equal in sweetness to sucrose thus no further intense sweetener will be required. ${ }^{7}$

Stevia as a non-nutritive sweetener can be used in small amounts to provide appropriate sweetness for chocolates containing polyols. It is derived from the leaves of the Stevia rebaudiana. The active ingredients are steviol glycosides and consist of sevioside or rebaudioside A. Rebaudioside A has the most desirable flavor profile and have 200 to 300 times the 
sweetness of sucrose. It has good stability at elevated temperatures and low $\mathrm{pH}^{7}$

Some researches have also used Stevia in chocolate composition. Aidoo et al. $^{\mathbf{1 1}}$ have studied the quality characteristics of sugar-free chocolates containing inulin/polydextrose bulking mixtures sweetened with Stevia and thaumatin extracts. Sucrose-free milk chocolates containing inulin and polydextrose were sweetened with Stevia. ${ }^{\mathbf{1 2}}$ The influences of the Stevia on the sweetness equivalence in bittersweet chocolates were determined by Azevedo et al. ${ }^{13}$ In the study of BelščakCvitanović et al. ${ }^{\mathbf{1 4}}$ sugar alcohols, dietary fibers, syrups and natural sweeteners were used as sucrose alternatives in the production of reduced sugar chocolates (50\% of cocoa parts) with enhanced bioactive profile. Stevia were used in the formulated chocolates.

Over the past decade, several researchers have studied the use of various methods and polyols as bulking sweeteners in the production of sucrose-free chocolates..$^{15,16}$ Rasouli Pirouzian et $a l .{ }^{15}$ studied the quality characteristics of sugar alcohols (maltitol and xylitol) sweetened milk chocolates by applying ball mill. Whereas compound chocolate was obtained from ball mill, also the differences exist in the formulation and the type of ball mill that were used. Unfortunately, suspected differences in melting behavior, color properties and microstructural characteristics of the milk chocolates (real chocolate) arising from this alternative process were not evaluated. Sokmen and Gunes ${ }^{\mathbf{1 6}}$ evaluated the influence of bulk sweeteners (maltitol, isomalt, and xylitol) and their particle size distribution only on rheological attributes of dark chocolates. They used paraffin bath for chocolate preparation. Although there are some studies evaluating the efficacy of polyols (isomalt, xylitol and maltitol) in chocolates, they have used different manufacturing methods such as pilot refiner and pilot conch. As a result, there are limited studies on developing sucrose-free chocolates by using ball-mill technique.

Therefore, the main objective of the current study was to use ball-mill method to investigate the effects of sucrose replacement with polyols such as isomalt, xylitol and maltitol as bulking agents and Stevia as a high intensity sweetener on the important physicochemical of sucrose-free milk chocolate.

\section{Materials and methods}

\section{Materials}

For the production of milk chocolate treatments, cocoa butter (Altinmarka, Turkey), cocoa mass (Altinmarka, Turkey; fat content: 52-56\%), sugar (SMS Kopuz, Turkey), whole milk powder (Cici Dairy, Turkey), sunflower lecithin (Lecico sun 400, Germany), polyglycerol polyricinoleate (PGPR 4120) (Palsgaard A/S, Denmark), ethyl vanillin (Rhodiarome, France), xylitol (Roquette Freres, France), maltitol (Roquette Freres, France with sweetening power of 0.80 compared with that of sucrose (=1)), isomalt LM-PF (Beneo-Palatinit GmbH, Germany - with sweetening power of 0.5 compared with that of sucrose $(=1)$ ) and Stevia SU200 (SteviaPack, Singapore - with sweetening power of 250 compared with that of sucrose $(=1)$ ) were used. Stevia was added in order to provide appropriate sweetness for chocolates containing isomalt and maltitol. Xylitol owns the same sweetness as sucrose therefore no additional intense sweetener was needed.

\section{Sample preparation}

Chocolate samples (with $41.28 \%$ fat) were produced in the laboratory ball mill (Tayas Company, Kocaeli, Turkey) with a capacity of $3 \mathrm{~kg}$. Homogenization performed at $40{ }^{\circ} \mathrm{C}$ at an agitator shaft velocity of $40 \mathrm{rpm}$, recycling the mass through the balls at an average speed of $12 \mathrm{~kg} \mathrm{~h}^{-1}$ of the recycling pump, for 3 hours. The compounds were added to the machine at the beginning of the production time. In the next step, a three-step tempering process $\left(33-35,24-25\right.$ and $25-26^{\circ} \mathrm{C}$ ) was performed (pilot temper metre (Aasted, Denmark: temper index: 4.5-5.5). After the molding and vibration processes, chocolate samples were cooled for $30 \mathrm{~min}$ at $5{ }^{\circ} \mathrm{C}$. The resulting samples were wrapped in aluminum foil and stored at $18{ }^{\circ} \mathrm{C}$. The control formulations included sucrose instead of polyols. Table 1 presents the formulation used in chocolate production.

In the cooling stage crystallization and maturation continues and produces between $40 \%$ and $60 \%$ of $\beta_{\mathrm{V}}$. In the storage process a well controlled maturation (80-90\%) is achieved. This time provides the necessary maturation conditions (full maturation) that are required to produce a more highly tempered chocolate. During the first $24-48 \mathrm{~h}$ of storage crystallization continues. Therefore, analysis was performed after at least $24 \mathrm{~h}$ of storage period.

Sucrose, maltitol, xylitol, isomalt, whole milk powder and cocoa mass used for the chocolate production contained $0.93 \pm$

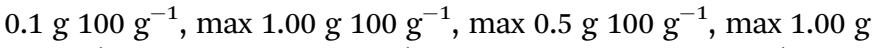

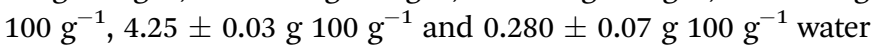
content, respectively. $D_{90}$ values of fine sugar, maltitol, xylitol, isomalt, whole milk powder, cocoa mass was determined as; 0.158 $\pm 0.009 \mathrm{~mm}, 0.090 \pm 0.007 \mathrm{~mm}, 0.090 \pm 0.004 \mathrm{~mm}, 0.063-0.090$ $\pm 0.005 \mathrm{~mm}, 0.174 \pm 0.003 \mathrm{~mm}, 0.152 \pm 0.008 \mathrm{~mm}$ respectively.

\section{Water activity determination}

Ten grams of each chocolate formulation was homogenized, then $2.00 \mathrm{~g}$ of the homogenized sample was used to measure the water activity $\left(a_{\mathrm{w}}\right)$ at $25{ }^{\circ} \mathrm{C}$ using a Lab-Master $a_{\mathrm{w}}$ (Novasina, Switzerland). ${ }^{17}$ Mean values from 4 replicate evaluations were determined.

Table 1 Formulations applied for preparation of milk chocolate samples $^{a}$ (g/100 g)

\begin{tabular}{lllll}
\hline Ingredient & Control & $\mathrm{T}_{1}$ & $\mathrm{~T}_{2}$ & $\mathrm{~T}_{3}$ \\
Fine sucrose & 33 & 0 & 0 & 0 \\
Isomalt & 0 & 33 & 0 & 0 \\
Xylitol & 0 & 0 & 33 & 0 \\
Maltitol & 0 & 0 & 0 & 33 \\
Stevia (ppm) & 0 & 660 & 0 & 330 \\
Cocoa butter & 27.5 & 27.5 & 27.5 & 27.5 \\
Cocoa mass & 13 & 13 & 13 & 13 \\
Whole milk powder & 26 & 26 & 26 & 26 \\
Sunflower lecithin & 0.3 & 0.3 & 0.3 & 0.3 \\
PGPR & 0.2 & 0.2 & 0.2 & 0.2 \\
Ethyl vanillin & 0.01 & 0.01 & 0.01 & 0.01
\end{tabular}

${ }^{a} \mathrm{~T}$ : treatment. 


\section{Moisture content}

The standard gravimetric method was used to define the moisture contents of the chocolates. ${ }^{18}$ Approximately $2 \mathrm{~g}$ of prepared chocolate sample was dried until a constant weight in Petri dish in air oven at $100{ }^{\circ} \mathrm{C}$. Loss in weight was reported as moisture content. Mean values from 4 replicate evaluations were determined.

\section{Particle size distribution (PSD)}

The particle size analysis performed by laser diffraction particle size analyzer (Horiba, Irvine, California, USA). Nearly $0.20 \mathrm{~g}$ of chocolate sample was diffused in vegetable oil (refractive index, $\mathrm{RI}=1.45)$ at ambient temperature $\left(20 \pm 2{ }^{\circ} \mathrm{C}\right.$ ) until an obscuration of 0.2 was established. Ultrasonic dispersion for $2 \mathrm{~min}$ to ensure the particles were freely diffused was maintained by stirring. Between each measurement, the detector and laser were aligned and the background was calibrated. The size distribution was quantified as the relative volume of particles in size bands presented as size distribution curves. Data analysis is based on the Mie theory. Parameters related with particle size distribution $\left(D_{3 / 2}(\mu \mathrm{m})\right.$, median; $D_{4 / 3}(\mu \mathrm{m})$, mean; $D_{90}(\mu \mathrm{m})$, largest particle size; specific surface area $\left(\mathrm{cm}^{2} / \mathrm{cm}^{3}\right) ; D_{10}(\mu \mathrm{m})$, smallest particle size and $D_{50}(\mu \mathrm{m})$ were evaluated. ${ }^{17}$ Mean values from 4 replicate evaluations were determined.

\section{Rheological properties}

Rheological characteristics of the chocolate formulations were determined using a strain-controlled rheometer (Anton Paar, MCR302, Austria). The chocolates were melted prior to measurement by incubation at $45^{\circ} \mathrm{C}$ for $60 \mathrm{~min}$ and pre-sheared (10 min, shear rate $=5 \mathrm{~s}^{-1}$ ) at $40^{\circ} \mathrm{C}$ before measurement cycles started. Then, shear stress was specified as a function of shear rate over a broad range 2 to $50 \mathrm{~s}^{-1}$. Each measurement took $180 \mathrm{~s}$ at $40{ }^{\circ} \mathrm{C}$ and 18 measurements were taken. ${ }^{19}$ Collected data were fitted with mathematical models such as Power law (eqn (1)), Bingham (eqn (2)), Herschel-Bulkley (eqn (3)) and Casson (eqn (4)). The two statistical indexes of Root Mean Square Error (RMSE) and coefficient of determination $\left(R^{2}\right)$ were calculated to select the best model defining the steady rheological attributes of the chocolates.

$$
\begin{gathered}
\sigma=\kappa \gamma^{n} \\
\sigma=\mu_{\mathrm{pl}}(\gamma)+\sigma_{0} \\
\sigma=\kappa \gamma^{n}+\sigma_{0} \\
\sigma 0.5=\kappa 10.5 \gamma 0.5+\sigma 00.5
\end{gathered}
$$

$\left[\sigma\right.$ indicates shear stress $(\mathrm{Pa}) ; \kappa$, consistency coefficient $(\mathrm{Pa} \mathrm{s})^{n} ; \gamma$, shear rate $\left(\mathrm{s}^{-1}\right) ; \mu_{\mathrm{pl}}$, plastic viscosity (Pa s); $\sigma_{0}$, yield stress (Pa); $\kappa_{1}$, Casson plastic viscosity ( $\mathrm{Pa} \mathrm{s}$ ); $n$, flow behavior index (dimensionless)]. Mean values from 4 replicate evaluations were determined.

\section{Hardness measurements}

The hardness of chocolates was determined using Texture Analyzer (Stable Micro Systems, TA-XT-plus, UK) with a penetration probe (needle $\mathrm{P} / 2$ ) and the trigger force of $5 \mathrm{~g}$. Hardness was expressed in kilogram force $\left(\mathrm{kg}_{\mathrm{F}}\right)$ and stated as the maximum penetrating force required for the needle to penetrate through a chocolate sample at $20^{\circ} \mathrm{C}$ over a interval of $3 \mathrm{~mm}$ at a stable rate of $1 \mathrm{~mm} \mathrm{~s}^{-1}$. Mean values from 4 replicate evaluations were determined.

\section{Color measurements}

Color of chocolate formulations were measured using a colorimeter (Chroma Meter CR-400, Konica Minolta, Japan-Light source: pulsed xenon lamp) calibrated with a white reference standard. The CR-400 was designed in diffusion illumination $0^{\circ}$ viewing angle geometry. The SCI-mode (Specular Component Included) was used with the color expressed in terms of the CIELAB system $L^{*}$ (luminance ranging from 0 (black) to 100 (white)), $a^{*}$ (green to red) and $b^{*}$ (blue to yellow). Chroma $\left(C^{*}\right)$ and hue $\left(h^{\circ}\right)$ values were measured by using these parameters according to the following equations;

$$
\begin{aligned}
& C^{*}=\sqrt{a^{*^{2}}+b^{*^{2}}} \\
& \mathrm{~h}^{\circ}=\arctan \mathrm{b} / \mathrm{a}^{*}
\end{aligned}
$$

\section{Melting properties}

Differential scanning calorimeter (DSC) (TA Q20, TA Instruments, USA) was applied to determine melting properties of the milk chocolates. $5 \mathrm{mg}$ chocolate sample was placed in pans with $40 \mathrm{~mL}$ volume and sealed with hermetic lid by a sample press. The onset temperature ( $\left.T_{\text {onset }}\right)$, peak temperature $\left(T_{\text {peak }}\right)$, end temperature $\left(T_{\text {end }}\right)$, peak width $\left(T_{\text {width }}\right)$ and $\Delta H$ (enthalpy of melting) parameters were obtained by heating of the pans from 0 to $60{ }^{\circ} \mathrm{C} \min ^{-1}$ heating rate. ${ }^{20}$ Mean values from 4 replicate evaluations were determined.

\section{Microstructural characteristics}

The structure and surface morphology of chocolate samples made with ball mill was observed using a MIRA3 FEG-SEM (Scanning Electron Microscope) (TESCAN, Czech Republic) under high vacuum and at an accelerated voltage of $10 \mathrm{keV}$. Prior to electron beam targeting, the cryo-fixation were performed and samples were frozen using cold slush nitrogen. Subsequently the samples were washed and dried at $-70{ }^{\circ} \mathrm{C}$ for $15 \mathrm{~min}$ to remove frost. Then the frozen samples were coated with a thin layer of gold in a separate device for direct observation.

\section{Sensory analysis}

Elected sensory properties included the appearance (surface color, brightness), aroma, taste, texture (structure, firmness), melting rate and overall acceptability of the chocolate samples. They were prepared with a set of three randomly coded samples, i.e., control milk chocolate, sucrose-free milk chocolate 
containing isomalt, sucrose-free milk chocolate containing maltitol and sucrose-free milk chocolate containing xylitol. The mentioned formulations were submitted to sensory evaluation, using a randomized complete block design. Sensory evaluation was carried out at University of Medical Sciences (Tabriz, Iran) by 30 trained panelists. Panelists ( 16 female and 14 male) who had ages between 26 and 45 assessed the chocolate samples. Sessions were performed in individual small rooms between 4:00 and 5:00 p.m., under fluorescent light. Samples were donated in white plastic dishes, and the panel was requested to assess the three-digit coded samples using a scale from 1 (extremely dislike) to 5 (extremely like), based on color, aroma, taste, melting rate and firmness of each sample. ${ }^{21}$ Sensory data were analyzed by the Tukey test for comparison of the samples. Approval for the study was obtained from the Ethics Committee of the Research Vice Chancellor of Tabriz University of Medical Sciences (Project no. 639730), and written satisfaction was given by all candidates.

\section{Statistical analysis}

Statistical analysis was performed using Minitab 16 and the level of significance was preset at $p<0.05$. The results were analyzed using the Tukey's test. MATLAB software (v. R2012a) was used for the fitting the rheological data to the mentioned four rheological models.

\section{Results}

\section{Water activity}

All milk chocolate samples displayed water activity values (Table $2)$ in acceptable limit $(<0.300)$ according to the results of previous studies. ${ }^{17}$ Also, Shadwell et al. ${ }^{22}$ stated that milk chocolate has a low water activity of $<0.400$. Though all chocolate samples illustrated remarkable variation in water activity as compared to the control $(p<0.05)$, no significant differences were noticed between samples produced with different sugar alcohols $(p>0.05)$.

\section{Moisture content}

Moisture content of the chocolate samples was within the acceptable range ( $<1.5 \mathrm{~g}$ per $100 \mathrm{~g})^{23,24}$ (Table 2). Xylitol significantly increased the moisture content of the chocolates. The higher moisture content of chocolates containing polyols can be described by the fact that polyols possess more hydroxyls as hygroscopic groups, ${ }^{6}$ which might absorb moisture from the chocolate mass during refining, ending in higher initial moisture content, contributing to agglomeration within the chocolate matrix.

\section{Particle size distribution}

Specific surface area, largest particle size, smallest particle size, median and mean particle size values for each chocolate formulation were determined as significantly different (Table 2) $(p<0.05)$. Using different bulking agents in milk chocolate under the same process conditions, had influences on PSD parameters and also rheological and textural properties of chocolates.

The mean largest particle size $\left(D_{90}\right)$ of control chocolate samples was found to be $38.16 \mu \mathrm{m}$ and chocolate containing xylitol illustrated $42.52 \mu \mathrm{m}$ (Table 2). The results illustrated that particle agglomeration occurred in the chocolates sweetened with polyols in contrast to the chocolate sweetened with sucrose. Based on $D_{90}$ value, it can be observed that the higher the moisture contents of the chocolates, the greater the agglomeration of the solid particles.

\section{Rheological properties}

Milk chocolate samples illustrated shear thinning behavior (Fig. 1), which is in accordance with former studies. ${ }^{17}$ As shown in Fig. 1 apparent viscosity of the treatments decreased as shear rate increased. At low shear rates, the apparent viscosity was considerably high, however with increasing the shear rate, they fall and any subsequent increase of shear rate did not present remarkable effect on this parameter. Using polyols increased the apparent viscosity of chocolate mass $(p<0.05)$.

\section{Casson plastic viscosity}

The apparent viscosities of chocolates samples were between 1.96-8.19 Pa s (Table 3). The trend of variations was similar to the trends noted with Casson viscosity and considerable differences $(p<0.05)$ were seen between chocolate samples. Sucrose-free chocolate samples including isomalt illustrated Casson viscosity values close to those of control chocolates $(p>$ 0.05). In contrast, the xylitol-containing samples $\left(T_{2}\right)$ showed higher viscosity than the other samples $(p<0.05)$.

Table 2 Water activity, moisture content and PSD values of milk chocolate samples prepared by different bulk sweeteners ${ }^{a}$

\begin{tabular}{|c|c|c|c|c|c|c|c|c|}
\hline Sample & $a_{\mathrm{w}}$ & $\begin{array}{l}\text { Moisture content } \\
(\mathrm{g} / 100 \mathrm{~g})\end{array}$ & \multicolumn{6}{|l|}{ PSD values } \\
\hline $\mathrm{T}_{1}$ & $0.238 \pm 0.002^{\mathrm{b}}$ & $1.11 \pm 0.02^{\mathrm{c}}$ & $5523.7 \pm 1.1^{\mathrm{b}}$ & $40.06 \pm 0.34^{\mathrm{b}}$ & $5.89 \pm 0.01^{\mathrm{b}}$ & $22.00 \pm 0.75^{\mathrm{bc}}$ & $16.09 \pm 0.34^{\mathrm{b}}$ & $19.06 \pm 0.56^{b c}$ \\
\hline $\mathrm{T}_{2}$ & $0.226 \pm 0.003^{\mathrm{b}}$ & $1.37 \pm 0.03^{\mathrm{a}}$ & $4968.4 \pm 0.9^{\mathrm{d}}$ & $42.52 \pm 0.13^{\mathrm{a}}$ & $6.73 \pm 0.04^{\mathrm{a}}$ & $28.00 \pm 0.63^{\mathrm{a}}$ & $16.86 \pm 0.14^{\mathrm{a}}$ & $22.45 \pm 0.21^{\mathrm{a}}$ \\
\hline $\mathrm{T}_{3}$ & $0.229 \pm 0.003^{\mathrm{b}}$ & $1.24 \pm 0.01^{\mathrm{b}}$ & $5216.2 \pm 1.5^{\mathrm{c}}$ & $41.23 \pm 0.27^{\mathrm{b}}$ & $6.09 \pm 0.05^{\mathrm{a}}$ & $25.00 \pm 1.14^{\mathrm{b}}$ & $16.15 \pm 0.42^{\mathrm{a}}$ & $20.58 \pm 0.63^{\mathrm{b}}$ \\
\hline
\end{tabular}

${ }^{a}$ Different letters within columns indicate significant differences $(P<0.05) . \mathrm{T}_{1}$ : treatments $1\left(100 \%\right.$ isomalt); $\mathrm{T}_{2}$ : treatment $2\left(100 \%\right.$ xylitol); $\mathrm{T}_{3}$ : treatments 3 (100\% maltitol). SSA: specific surface area, $D_{4 / 3}$ mean, $D_{3 / 2}$ median, $D_{10}, D_{50}$ and $D_{90}$, respectively, represent $10 \%, 50 \%$ and $90 \%$ of all particles finer than these sizes. 


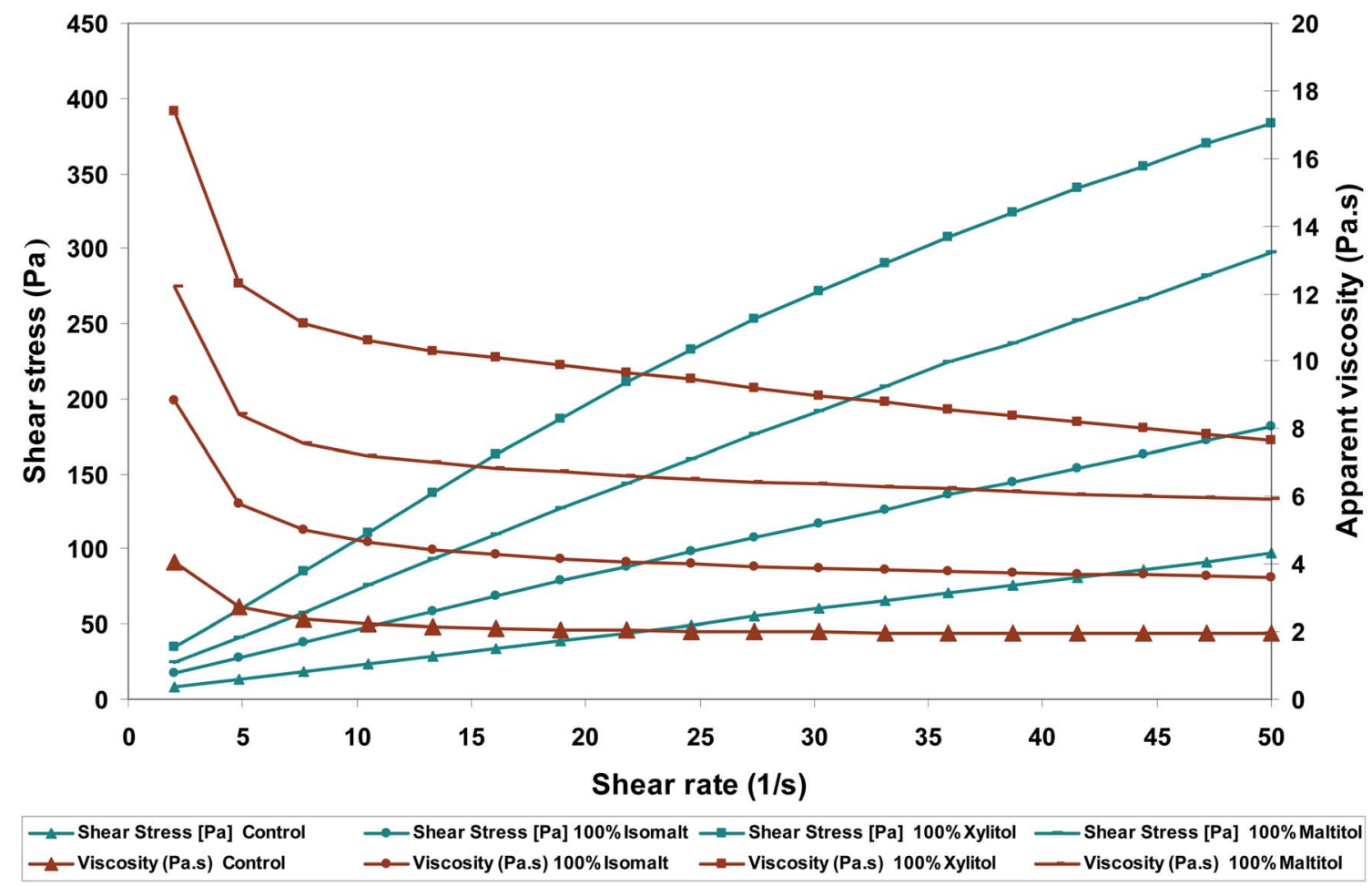

Fig. 1 Effects of sugar replacers on shear stress and apparent viscosity-shear rate rheograms of functional milk chocolates.

\section{Casson yield stress}

The data obtained from the model (Table 3) demonstrated that the yield stress significantly increased with the addition of xylitol $(p<0.05)$. However the yield value of chocolates produced with isomalt and maltitol were not statistically $(p>0.05)$ higher than that of control (Table 3).

\section{Hardness}

Among the sucrose-free chocolate samples, formulations containing xylitol illustrated the least hardness values with a mean value of $4.54 \mathrm{~kg}_{\mathrm{F}}$ (Table 3). Chocolate samples containing $100 \%$ maltitol was the hardest with an average of $5.14 \mathrm{~kg}_{\mathrm{F}}$. Aidoo et $a .^{25}$ reported that chocolate samples produced with high concentrations of sucrose replacers had higher hardness values in comparison to control.

\section{Color properties}

Color parameters of milk chocolates produced with different polyols and sucrose are presented in Table 4. All three parameters related with color, namely lightness $\left(L^{*}\right)$, chroma $\left(C^{*}\right)$ and hue $\left(h^{\circ}\right)$ values, decreased with using polyols as bulk sweeteners. Replacing sucrose with polyols ended in less brighter chocolate. $L^{*}$ and $C^{*}$ values for samples produced with xylitol were not significantly different from control but were significantly different from other sucrose-free chocolates $(p<0.05)$. Hutching $\mathrm{s}^{26}$ reported that the color properties of a product could be affected by absorptivity and scattering factors.

\section{Melting properties}

There were significant differences between $T_{\text {onset }}, T_{\text {peak }}$ and $\Delta H$ values of control chocolates in comparison with chocolates

Table 3 Hardness and rheological parameters of milk chocolate samples ${ }^{a}$

\begin{tabular}{lllll}
\hline & & \multicolumn{2}{l}{ Rheological parameters } & \\
\cline { 3 - 5 } Sample & Hardness $\left(\mathrm{kg}_{\mathrm{F}}\right)$ & $\begin{array}{l}\text { Apparent viscosity } \\
(\text { Pa s) }\end{array}$ & Casson viscosity (Pa s) & Casson yield (Pa) \\
\hline Control & $4.46 \pm 0.29^{\mathrm{c}}$ & $1.96 \pm 0.009^{\mathrm{b}}$ & $1.60 \pm 0.093^{\mathrm{b}}$ & $0.67 \pm 0.306^{\mathrm{b}}$ \\
$\mathrm{T}_{1}$ & $4.78 \pm 0.56^{\mathrm{b}}$ & $3.7 \pm 1.05^{\mathrm{b}}$ & $2.78 \pm 0.091^{\mathrm{b}}$ & $2.71 \pm 0.457^{\mathrm{b}}$ \\
$\mathrm{T}_{2}$ & $4.54 \pm 0.12^{\mathrm{c}}$ & $8.19 \pm 0.86^{\mathrm{a}}$ & $6.11 \pm 0.63^{\mathrm{a}}$ & $6.94 \pm 1.017^{\mathrm{a}}$ \\
$\mathrm{T}_{3}$ & $5.14 \pm 0.34^{\mathrm{a}}$ & $6.07 \pm 0.89^{\mathrm{a}}$ & $4.91 \pm 0.16^{\mathrm{a}}$ & $2.61 \pm 0.583^{\mathrm{b}}$
\end{tabular}

${ }^{a}$ Different letters within columns indicate significant differences $(P<0.05) . \mathrm{T}_{1}$ : treatments $1(100 \%$ isomalt $) ; \mathrm{T}_{2}$ : treatment $2\left(100 \%\right.$ xylitol); $\mathrm{T}_{3}$ : treatments $3\left(100 \%\right.$ maltitol). *Apparent viscosities are stated at a constant shear rate $\left(40 \mathrm{~s}^{-1}\right)$ for comparison aims. 
Table 4 Color and melting properties of milk chocolate samples ${ }^{a}$

\begin{tabular}{|c|c|c|c|c|c|c|c|c|}
\hline Sample & \multicolumn{3}{|c|}{ Color parameters } & \multicolumn{5}{|c|}{ Melting properties } \\
\hline $\mathrm{T}_{1}$ & $51.47 \pm 0.33^{\mathrm{c}}$ & $15.60 \pm 0.36^{\mathrm{b}}$ & $47.10 \pm 0.76^{\mathrm{d}}$ & $17.4 \pm 0.18^{\mathrm{c}}$ & $29.7 \pm 0.23^{\mathrm{c}}$ & $37.1 \pm 0.01^{\mathrm{a}}$ & $4.87 \pm 0.4^{\mathrm{a}}$ & $34.6 \pm 0.45^{\mathrm{ab}}$ \\
\hline $\mathrm{T}_{2}$ & $56.03 \pm 0.47^{\mathrm{a}}$ & $17.51 \pm 0.08^{\mathrm{a}}$ & $49.84 \pm 0.32^{\mathrm{b}}$ & $18.7 \pm 0.09^{\mathrm{b}}$ & $30.8 \pm 0.05^{\mathrm{b}}$ & $37.3 \pm 0.19^{\mathrm{a}}$ & $4.79 \pm 0.2^{\mathrm{a}}$ & $33.5 \pm 0.23^{\mathrm{b}}$ \\
\hline $\mathrm{T}_{3}$ & $54.80 \pm 0.16^{\mathrm{b}}$ & $17.15 \pm 0.51^{\mathrm{a}}$ & $48.92 \pm 0.15^{c}$ & $19.0 \pm 0.16^{\mathrm{b}}$ & $30.8 \pm 0.01^{\mathrm{b}}$ & $37.7 \pm 0.16^{\mathrm{a}}$ & $4.93 \pm 0.4^{\mathrm{a}}$ & $35.4 \pm 0.15^{\mathrm{a}}$ \\
\hline
\end{tabular}

${ }^{a}$ Different letters within columns indicate significant differences $(P<0.05) . \mathrm{T}_{1}$ : treatments $1\left(100 \%\right.$ isomalt); $\mathrm{T}_{2}$ : treatment $2\left(100 \%\right.$ xylitol); $\mathrm{T}_{3}$ : treatments 3 (100\% maltitol).

produced with polyols $(p<0.05)$. Chocolates sweetened with polyols and sucrose exhibited similar $T_{\text {end }}$ values (Table 4). Nevertheless, samples produced with polyols exhibited slightly lower $T_{\text {onset }}$ and $T_{\text {peak }}$ temperatures than sucrose including chocolate, however higher peak widths and enthalpy than the control samples.

\section{Microstructural characteristics}

The presence of agglomerates in chocolates containing polyols can be clearly observed in Fig. $2 b$, $d$ and $f$. The chocolate sweetened with sucrose which contained the lowest amount of moisture and/or amorphous part showed more dispersed and less agglomerate particles (Fig. 2a); however the samples containing polyols exhibited more particle agglomeration.

\section{Sensory analysis}

Among sucrose-free chocolates, samples containing xylitol received the best scores (Fig. 3a-c) in the case of all sensory properties. Isomalt including sample was determined with the lowest taste scores, acceptability and little aftertaste. The appearance of all chocolate formulations ranged from 3.97 to 4.85 with control and xylitol samples obtaining similar and highest preference $(p>0.05)$ (Fig. 3c).

Samples made with xylitol received a highest chocolate aroma of any of the sucrose-free samples $(p<0.05)$ (Fig. 3b). In terms of taste attribute, sample produced with xylitol was the closest to conventional, due to its high sweetness and cooling effect, which might be the reasons for the better acceptability and scores for these attributes. A strong synergistic taste enhancement was distinguished in chocolates containing xylitol; however low taste acceptance $(p<0.05)$ was reported from chocolates containing isomalt (Fig. 3b). The result showed that using a bulking sweetener with cooling effect could increase the sweet taste because synergism interaction occurs and dissemination of taste happens.

Texture scores of chocolate samples ranged from 3.92 to 4.84 (Fig. 3a). Sucrose replacement with maltitol and isomalt significantly lowered the texture acceptability while chocolate containing xylitol was the closest to reference in terms of texture $(p<0.05)$. The assessment of melting rate showed that chocolate samples containing maltitol and isomalt had significantly $(p<$ 0.05) lower preference than the control (Fig. 3a).

\section{Discussion}

Water activity is an important parameter in specifying chocolate stability and quality. Meantime the raw ingredients, the surface area of the ingredients and processing terms such as; the temperature, time and the humidity may influence this parameter. ${ }^{27}$

Xylitol has low molecular weight and it exerts a higher osmotic pressure and thus displays a lower water activity. ${ }^{9}$ Also, maltitol as an osmotic agent has a certain role in reducing water activity. ${ }^{22}$ It can be concluded that using these bulking agents does not have a dissenting effect on the $a_{\mathrm{w}}$ of the chocolate and hence shelf life and storage stability.

In the study of Saputro et al. ${ }^{28}$ high amounts of sugar substitutes with high hygroscopic nature showed higher moisture content. They used alternative (applying both Stephan mixer and ball mill) and conventional technique (refining and conching) to investigate the effect of palm sugar on the quality properties of dark chocolate. Results indicated that chocolate prepared with palm sugar and alternative method exhibited a higher degree of agglomeration. The researches concluded that the conventional method evaporates moisture more efficiently, resulting in a lower particle agglomeration in chocolates. Furthermore, Shourideh et al. ${ }^{29}$ prepared the chocolate masses with laboratory ball mill and reported that the presence of hydrophilic groups on the chemical formula of replacers was the reasons for preserving and increasing the moisture level in comparison to control samples.

Largest particle size and solids specific surface area are the two key parameters for chocolate manufacture. ${ }^{30}$ The particle diameter determines chocolates textural character, and specific surface area is related with flow attributes. Specific surface area has been inversely associated with ingredient PSD in chocolate. ${ }^{16}$ One of the most substantial factors affecting the viscosity and the texture of the chocolate is its size of particles. For achieving an appropriate particle size, refining, conching and also ball mill process conditions such as rpm and time duration during chocolate processing play a key role. ${ }^{31}$

Particle size of the treatments was in the acceptable range $(<35 \mu \mathrm{m})$ reported for chocolate. ${ }^{32}$ Polyols possess different numbers of hydrophilic active sites. These hydroxyl groups generally are involved in intermolecular hydrogen bonds. ${ }^{6}$ During chocolate processing these groups become more active and form intermolecular (non-polar) interactions in chocolate 

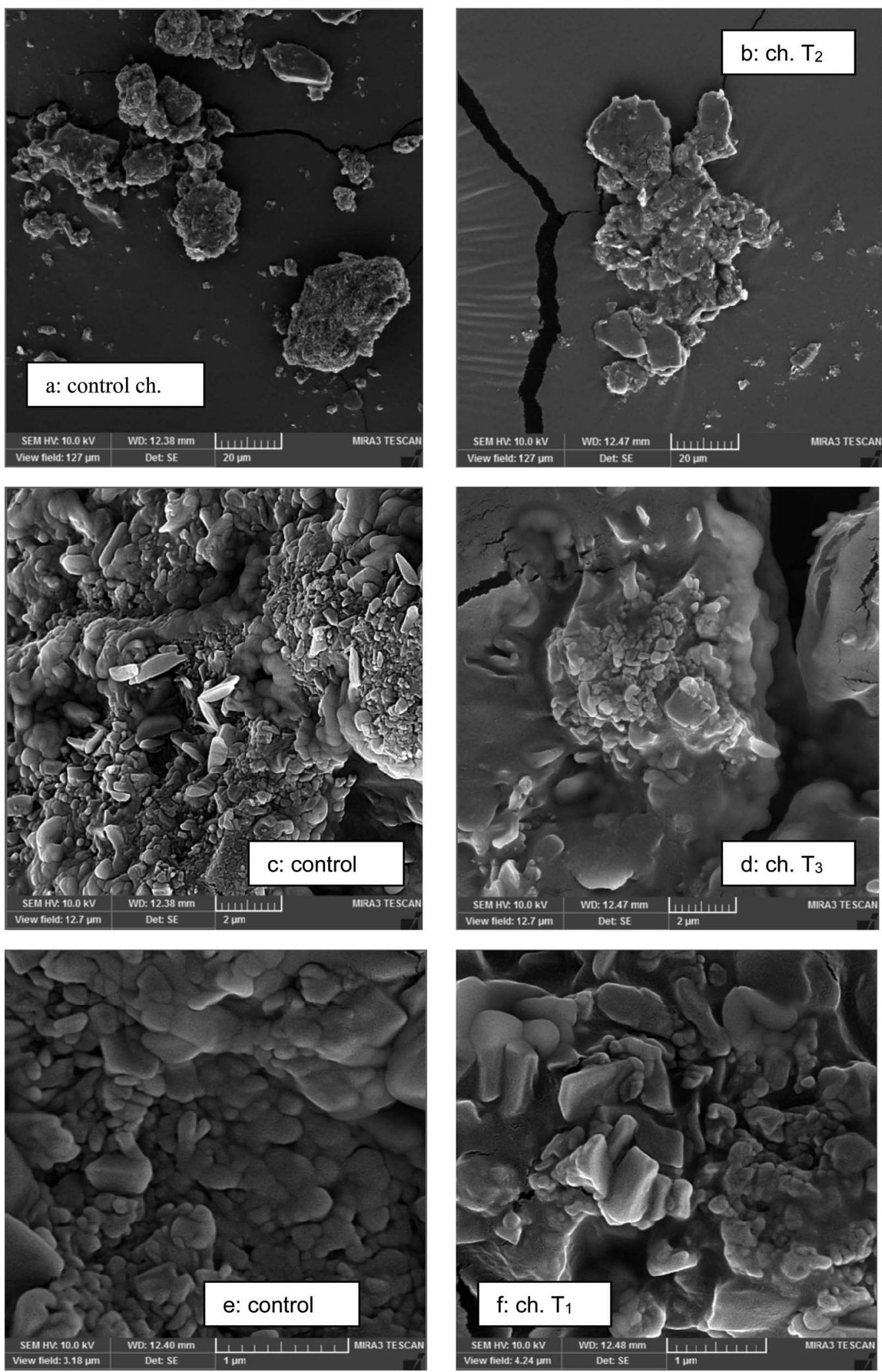

Fig. 2 Particle agglomeration of chocolates sweetened with sucrose and polyols obtained with scanning electron microscopy: (a, c and e) control chocolates; (b, $d$ and f) sucrose-free chocolates.

mass. This results in particle agglomeration. Therefore, the particle size of the chocolate will not drop significantly due to high degree of agglomeration. ${ }^{15}$ High moisture and the presence of hygroscopic polyols might create the presence of more amorphous part during chocolate production, causing to particles agglomeration. ${ }^{33}$ 


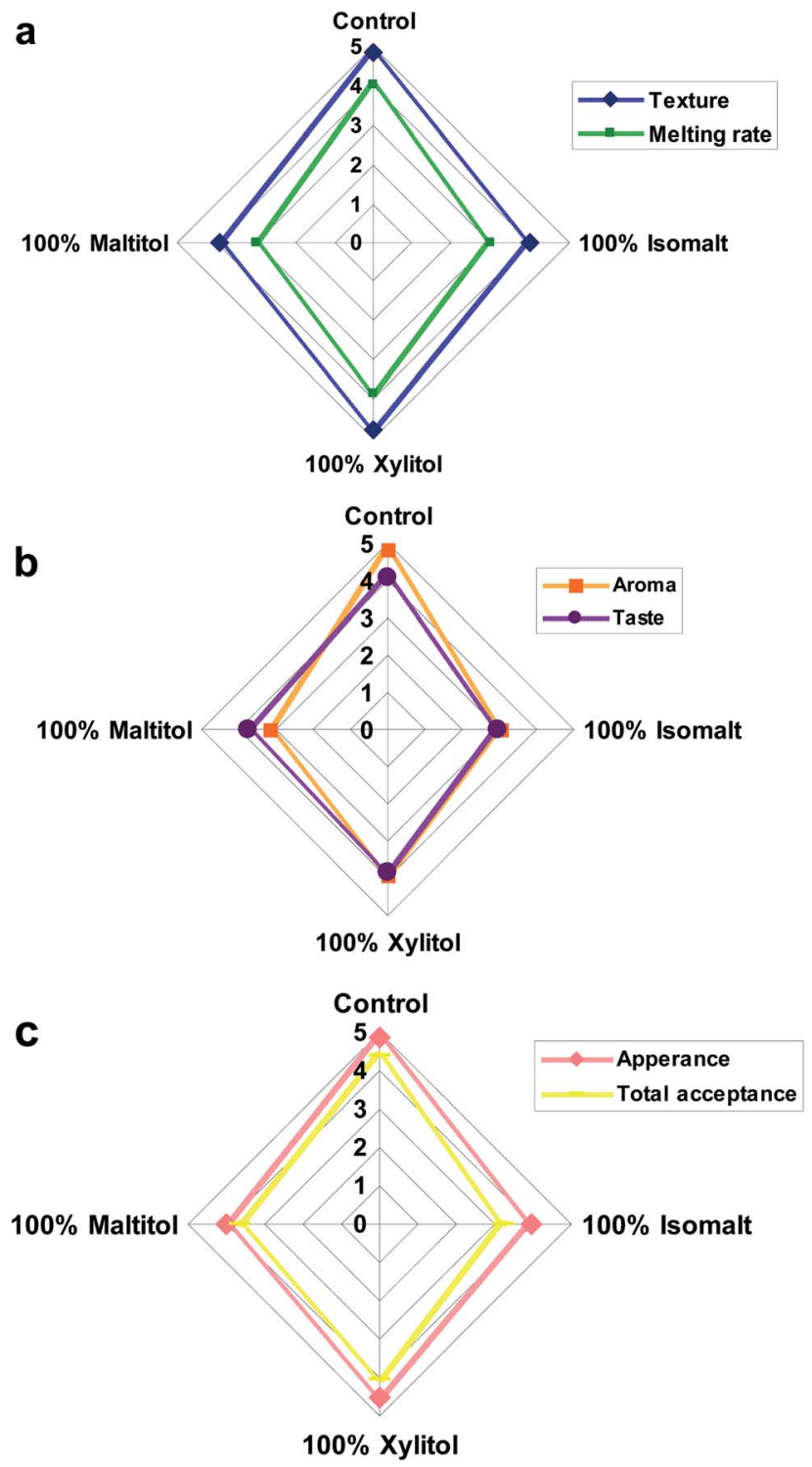

Fig. 3 Spider chart representing (a) melting rate and texture, (b) aroma and taste and (c) appearance and total acceptance of chocolate samples.

The presence of moisture in chocolate could dissolve sugar particles or even develop sticky patches on the surfaces of the sugar particles, forming particle agglomeration, which in turn influences particle-particle interactions. In the study of Saputro et al..$^{34}$ the chocolate samples with the highest moisture content (100\% palm sugar) displayed the highest degree of agglomeration, nearly no agglomeration was seen in chocolate sweetened with sucrose. They concluded that the agglomerates were created due to the presence of moisture in the chocolate which may also enforce the formation of amorphous sugar during chocolate production, causing the sugar particles to stick together and form agglomerates. The moisture content of palm sugar was considerably higher than that of sucrose.
Moreover Saputro et al. ${ }^{35}$ reported that the particle size of the chocolate varied depending on the milling time. In their study, the chocolates prepared with 30 and 45 min milling time had smaller particles than the reference chocolates produced with 15 min milling time. Also that particle agglomeration did not occur; supporting the fact that moisture was present in very low amount.

Chocolates prepared with palm sugar and alternative method (Stephan mixer and ball mill) exhibited higher particle size due to higher degree of agglomeration. ${ }^{28}$ In a study by Gomes et al. ${ }^{36}$ it was shown that the particle size of chocolate samples (produced in a three-cylinder pilot mill and pilot conch) containing maltitol and lactitol ranged between 19 to 21 $\mu \mathrm{m}$ and it was in acceptable limit $(<30 \mu \mathrm{m})$. Toker et al. ${ }^{31}$ investigated the effect of agitator shaft speed (40-60 rpm) and refining time $(10-30 \mathrm{~min})$ of ball mill on some physical parameters of compound chocolate. The result illustrated that the particle size of the compound chocolates decreased significantly with increasing shaft speed and refining time. Results illustrated that the optimum particle size of $<30 \mu \mathrm{m}$ could be obtained in milk chocolate by using ball mill method for sucrose-free milk chocolate.

In the next stage the shear stress $v s$. shear rate data was fitted with mathematical models such as Power law, Bingham, Herschel-Bulkley and Casson. The Casson model presented the best fitting for all the chocolate samples because of its highest $R^{2}$ and lowest RMSE values (Table 5). Casson model as a suitable model for determination of the flow behavior of different types of chocolates has been accepted. ${ }^{37}$

The content and types of the compounds used in the recipe, particle size distribution and processing strategy are the key factors influencing chocolate viscosity. ${ }^{38}$ Control samples showed the lower values of Casson plastic viscosity which is initially caused by low mean particle size (Table 2). Particles that are smaller in size, contain more surface area, thus in smaller particles, more fat will coat the solid particles and reduces the viscosity. ${ }^{37}$

As mentioned above the content and type of ingredients such as fat content has a critical role in chocolate viscosity. According to the formulation used (Table 1 ) in the current study, nearly $41.28 \%$ fat content were calculated in the chocolate recipe. This amount is different from other researchers. Abbasi and

Table 5 Effects of sugar replacers on fitting of experimental data with rheological models in terms of $R^{2}$ and RMSE parameters ${ }^{a}$

\begin{tabular}{|c|c|c|c|c|c|c|c|c|}
\hline \multirow[b]{2}{*}{ Samples } & \multicolumn{2}{|c|}{ Power law } & \multicolumn{2}{|c|}{ Bingham } & \multicolumn{2}{|c|}{$\begin{array}{l}\text { Herschel- } \\
\text { Bulkley }\end{array}$} & \multicolumn{2}{|c|}{ Casson } \\
\hline & $R^{2}$ & RMSE & $R^{2}$ & RMSE & $R^{2}$ & RMSE & $R^{2}$ & RMSE \\
\hline Control & 0.998 & 1.021 & 0.999 & 0.153 & 0.998 & 0.119 & 0.999 & 0.085 \\
\hline $\mathrm{T}_{1}$ & 0.999 & 1.690 & 0.999 & 1.368 & 0.999 & 0.380 & 0.999 & 0.063 \\
\hline $\mathrm{T}_{2}$ & 0.997 & 5.253 & 0.988 & 12.25 & 0.995 & 4.841 & 0.998 & 0.295 \\
\hline $\mathrm{T}_{3}$ & 0.999 & 1.751 & 0.998 & 2.965 & 0.999 & 1.221 & 0.999 & 0.081 \\
\hline
\end{tabular}

${ }^{a} R^{2}=$ determination coefficient, RMSE: Root Mean Square Error. $\mathrm{T}_{1}$ : treatment $1\left(100 \%\right.$ isomalt); $\mathrm{T}_{2}$ : treatment $2\left(100 \%\right.$ xylitol); $\mathrm{T}_{3}$ : treatment 3 (100\% maltitol). 
Farzanmehr ${ }^{39}$ have optimized the formulation of prebiotic milk chocolate. They have used inulin as a prebiotic ingredient and two bulking agents including maltodextrin and polydextrose instead of sucrose. The fat content of chocolate formulations was $24.30 \%$. In the study of Sokmen and Gunes ${ }^{16}$ effect of bulk agents (maltitol, xylitol and isomal) on rheological properties of dark chocolate were investigated. The fat content of the chocolate formulations were calculated as $24.47 \%$. Shah et al. ${ }^{12}$ prepared sucrose-free milk chocolate with different sweeteners (Stevia, inulin and polydextrose). The total fat content was $31.17 \%$. The fat content of milk chocolate formulations in the study of konar $^{17}$ was $35.4 \%$.

Bouzas and Brown ${ }^{37}$ stated that chocolate mass with smaller particles size will yield in the lowest viscosity. Pajin et al. ${ }^{\mathbf{4 0}}$ studied the rheological attributes of soya milk chocolate obtained from a ball mill. The results indicated that the impact of the refining time on the chocolate viscosity is related in a particle size reduction. In the study of Saputro et al. ${ }^{28}$ the rheological attributes in the chocolate samples was related to the processing technique and type of sweetener. Alternative technique which was less effective in evaporating moisture than conventional technique led to a higher degree of agglomeration and thus higher Casson viscosity.

In the presence of water, the crystals of the sweetener dissolve and the interactions between sugar particles will increase. ${ }^{33}$ This can increase the internal friction resulting in higher viscosity. Among the polyols studied, xylitol has the highest hygroscopicity thus it will absorb the moisture from the environment manifesting a higher viscosity. ${ }^{6}$

If higher viscosity of the samples produced with xylitol might have result in problems in production steps, which can be eliminated by optimizing emulsifier concentration (Lecithin and PGPR) and by adjusting processing temperature considering denaturation temperature of milk proteins.

The interactions between particles in chocolate suspension and interfacial properties influence the yield value of the product. ${ }^{41}$ Due to xylitols spatial structure there are more active and free $-\mathrm{OH}$ groups thus more interactions between particles take place. ${ }^{6}$ This phenomena leads to higher yield value and it means more energy is needed to initiate the flow.

In the study of Rodriguez Furlan et al. ${ }^{41}$ sugar-free chocolate containing Stevia and sucralose showed a higher viscosity than the control samples. They reported that greater concentration of suspended solids will generate higher creep resistance. Pajin et $a l .{ }^{40}$ reported that the yield value in the chocolate samples (produced in a ball mill) reached after 60 min of refining was closest to the optimum range (from $6.00-8.00 \mathrm{~Pa}$ ) of milk chocolate. They suggested the high yield value could be reduced by adding PGPR. Saputro et al. ${ }^{28}$ stated lower yield value for control chocolates obtained from conventional processing in comparison to alternative method. Increased fat content due to moisture evaporation during conventional method could be one reason for lower yield value.

Schantz and Rohm ${ }^{42}$ reported that the yield stress of the milk chocolate is considerably reduced by using mixtures of almost $30 \%$ lecithin and 70\% PGPR. Particular interactions are created due to PGPR and cocoa butter bonding. These new formed structures create spaces among sugar particles and could reduce particle-particle interaction thus reduces the viscosity of the product. As a result, additional studies of emulsifier optimization should be carried out in order to produce chocolate with the addition of polyols, especially to improve rheological parameters. This results in yield value reduction without considerable changes to the overall chocolate formulation thus can be economically helpful to the manufacturer.

The differences in hardness can be related to the differences in composition of sweeteners used in chocolate samples. ${ }^{43}$ Polyols possess several numbers of hydrophilic active sites. These hydroxyl sites generally are involved in intermolecular bonds. During chocolate production these groups become more active and forms intermolecular (non-polar) interactions between particles in chocolate mass. For instance all nine hydroxyl groups of maltitol are involved in covalent bonds and produce chains causing higher hardness. ${ }^{6}$

Stortz and Marangoni ${ }^{\mathbf{4 4}}$ discussed the influence of excessive water in chocolate. They have reviewed main strategies to produce heat resistant chocolate. One method is to incorporate some water (4-20\%) by direct or indirect techniques to enhance network microstructure. By this technique some surfaces of sugar will not be coated by fat. The second stage was to heat the chocolate $\left(65.5{ }^{\circ} \mathrm{C}\right)$ and therefore most of the sugar was dissolved in the water. For removing such a large amount of water from the product and homogenizing chocolate will need a considerable change in the way chocolate is manufactured, requiring additional equipment, such as a homogenizer and a vacuum evaporator. This will result the cost of manufacturing. Water addition will increase the chocolate viscosity, leads to undesirable sugar bloom. Moreover the product will be quite unlike conventional chocolate products in its described appearance and texture. Also some studies stated that absorbing moisture by sucrose substitutes lead to hardness of final chocolate. ${ }^{29}$

The high brightness of control samples could be related to the sucrose diffusing character. Sucrose contains multidimensional crystals with sharp edges scattering the light in all directions from the matrix. Chocolates with more interparticle interactions $\left(T_{2}\right)$ are denser and they can scatter more light and thus seem lighter in comparison with other sucrosefree chocolates. ${ }^{23}$ Therefore the magnitude of color parameters increased. Another possible reason may be effects of sweetener type on fat crystal size. Sucrose may act as a nucleating agent and effect crystallization and pre-crystallization. Alternative sweeteners (e.g. polyols) may not behave as sucrose. In the study of Toker et $a l^{31}$ the magnitude of color parameters of compound chocolate increased with increasing shaft speed and refining time. They finalized that increasing the shaft speed and production time generated smaller particles with more particle interactions scattering more light resulting in lighter samples. It can be concluded that the compositional differences (the type of sweetener) plays a crucial role in color properties of the final product as it directly affected the color of the product.

Briones et $a l .{ }^{45}$ investigated the effect of surface topography on color and gloss of chocolate samples. For this purpose, 
different surface roughnesses of six chocolate batches were prepared by molding over sandpaper of different graininess. Surfaces of sandpaper and chocolate batches were highly correlated with two parameters including average roughness and the area-scale fractal complexity. Gloss of chocolate surfaces diminished exponentially as roughness increased while color $\left(L^{*}\right.$, lightness and whiteness index) decreased linearly. The structure of the surface of chocolate samples played a decisive role in visual quality appearance.

The differences in melting properties ( $T_{\text {onset }}$ and $\left.T_{\text {peak }}\right)$ in chocolate could be related to the differences in moisture content and particle sizes, different structure and configuration of sugars and intermolecular bonds. Due to different chemical structure of polyols they have a faster solubility rate than sucrose therefore facilitates the melting of cocoa butter because it reaches sooner to the oral temperature.

Regarding the melting, the chocolate has specific properties, since its continuous phase is fat, but the other compounds (such as, sugar, cellulose compounds milk powder, cocoa powder, or cellulose extracted from cocoa beans) have high solubility in water. These ingredients cause changes in the edible properties and they can affect the melting properties of cocoa butter. So the melting properties of cocoa butter are related to the solubility properties of other ingredients. Any changes in raw materials such as sugars and other bulking agents - especially sugar alcohols - due to its higher - $\mathrm{OH}$ groups, results in very fast solubility in the mouth. This has a direct impact on the degree of melting in the mouth. Because any alteration in sugars, especially sugar alcohols with high -OH groups, increases the disintegration of ingredients in the mouth and cocoa butter melts faster. Further disintegration results in more conductivity (faster heat transfer) and faster melting of fat. In other words, the fat molecules will heat up and melt more quickly. Therefore, the melting point of cocoa butter is related to other ingredients of the chocolate.

Regarding the devise measurements, it can be stated that due to the presence of high $-\mathrm{OH}$ groups of sugar alcohols, the repulsive force is formed inside the emulsion at any moment. When the chocolate is heated in the device, by breaking down the dative and covalent bonds, because the sugar molecules are hydrophilic, and the fat molecules are hydrophobic, disintegration and dissociation occurs more quickly and the product melts faster.

Saputro et al. ${ }^{33}$ reported lower $T_{\text {onset }}$ and $T_{\text {peak }}$ temperatures in chocolates containing palm sugars in comparison to control due to the higher moisture content and thus development to more amorphous nature of samples. Variations in enthalpy values could have resulted from the differences in - $\mathrm{OH}$ groups that results in more intermolecular bonds and high degree of polymerization and as a result more energy is required for full melting of the product. An increase in the melting profile of chocolate has been reported formerly with the increasing degree of inulin polymerization. ${ }^{12}$

Saputro et al. ${ }^{28}$ reported an equal peak melting temperature in the range of $33.7-34.0^{\circ} \mathrm{C}$ for all type of chocolates, however in terms of sugar melting, irrespective of the processing techniques, palm sugar showed a lower melting temperature than sucrose. Chocolate samples formulated with palm sugar indicated significantly lower $(p<0.05) T_{\text {onset }}$ and $T_{\text {peak }}$ than chocolates prepared with sucrose. The presence of high moisture (obtained from alternative method) acts as plasticizer ending in a lower sugar melting $T_{\text {peak }}$ temperature in chocolate. Moreover in their research regardless of the sweetener type, alternative method obtained chocolates with a lower enthalpy (\%) than conventional method. It was proved that chocolate having higher moisture content showed a lower melting point and a narrower peak area than chocolate having less moisture.

Shah et al. ${ }^{12}$ prepared sucrose-free milk chocolates with different types of commercial inulin or polydextrose as bulking agents. The melting point temperature for all chocolate samples ranged from $30.8{ }^{\circ} \mathrm{C}$ to $32.6{ }^{\circ} \mathrm{C}$. The control and samples prepared with inulin HP had significantly $(p<0.05)$ higher melting temperature than the others. The authors explained that the differences in melting points could be related to the inulin and its average degree of polymerization, because the presence of the thicker crystals in inulin has higher melting points.

Sucrose replacement with the inulin/polydextrose and Stevia/thaumatin extracts showed that sucrose substitution by the sugar replacers produced changes in crystallinity and melting properties. ${ }^{11}$ The onset temperature was slightly higher for the control sample than for the sucrose-free chocolates indicating a slight delay in start of melt for the control. The enthalpy of melt was also higher for the control than the sucrose-free chocolates. The above outcomes were associated with the microstructural behavior of the bulk ingredients.

As a result it can be concluded that successful new product development needs care relating texture of products and their properties such as, melting profiles, based on an understanding of factors such as particle size distribution and ingredient composition.

The appearance of the sugar crystals and particle-particle interactions in the chocolate samples can be seen in Fig. 2C and D. Micrographs illustrated an obvious variation in microstructure of the chocolates sweetened with sucrose and different polyols. The sugar crystals can be seen in chocolate sweetened with sucrose that could be recognized with a comparatively big size of crystals with sharp edges. However, similar sugar crystals could not be seen in chocolate prepared with polyols. Also in polyols, more interactions between particles and agglomerates could be observed (Fig. 2F). Also in the study of Saputro et al. ${ }^{28}$ the chocolate samples prepared with palm sugar and alternative method illustrated a higher degree of particle agglomeration because of high moisture of sugar replacers. The qualitative structural data observed by micrographs provided a mechanistic explanation for quantitative variations in chocolate characteristics.

Chocolate color affects the expected and perceived sensory properties. In control sample, the multi-dimensional crystals of the sucrose have sharp edges scattering many colors of light in all directions and that gives it its color but in the case of polyols due to the different arrangement of crystals the minimum light reflection happens. Using sweeteners with cooling effect increases the perceived sweetness of the product. On the other hand, a strong preference for aroma is associated with a higher 
sweet taste. The initial aroma release is higher from a food with higher sweetness. ${ }^{46}$

In the present study, sucrose-free formulations containing maltitol and isomalt were produced by addition of some amount of Stevia to accommodate the sweetness intensity of sucrose. Certain differences in taste perception among isomalt samples could be resulted from the inherent attributes of Stevia used in the formulation (Table 1). Therefore the slight bitterness and astringency taste between other chocolates is related to the inherent bitterness of Steviol glycosides. ${ }^{47}$ Bitterness and undesirable aftertaste significantly masks the sweetness of Stevia.

Texture is a sensory character and is affected by the food structure such as molecular, microscopic and macroscopic properties. ${ }^{48}$ Probably high concentration of the sugar replacers causes the hardening effect of the chocolates. Some studies also reported that total sucrose substitution in chocolate end in the hardest chocolate.

Melting rate is related to the structure and texture of the bulking agents. It has been assumed that polyols do not properly diffuse into the fat phase as well as sucrose due to their high amount of hydroxyl groups. These $-\mathrm{OH}$ groups has tendency to escape from continuous phase.

There are some studies reporting the effects of bulking agent's addition on sensory attributes of chocolate. In the study of Homayouni Rad et al. ${ }^{49}$ sucrose replacer improved the sensory properties. Variations in ingredients composition, particle size distribution and processing techniques are the reasons for different sensory quality of chocolates. The most usual functional interest of xylitol in chocolate is modulation of the sweetness during melting in the mouth and upgrading the chocolates taste.

\section{Conclusions}

Milk chocolate samples prepared with polyols by using ball mill method in comparison to sucrose represented higher agglomeration which modifies the fineness of the chocolate and ends to higher plastic viscosity. In the case of processing techniques, using ball mill seems to be less efficient in evaporating moisture than the conventional processing. Findings from the current study will present a more cost-effective method for chocolate preparation which provides shorter processing times for small chocolate industries. More studies are required for further progress in the ball mill as an alternative processing technique to evaporate more moisture ending in high quality chocolate prepared with polyols. If the changing of bulking agent raises difficulties in the preparing of chocolate, it can be suggested to be adjusted PGPR/lecithin amounts or temperature of the process. Furthermore, different combinations of bulk sweeteners can be used to produce sucrose-free chocolate with appropriate rheological, melting and other physical quality properties.

\section{Conflicts of interest}

There are no conflicts to declare.

\section{Acknowledgements}

This work was supported by the Ministry of Health and Medical Education of Iran [Project No 639730]. The authors would like to acknowledge Research Vice Chancellor of Tabriz University of Medical Sciences as well as the Tayas Food Company (Kocaeli, Turkey). We also wish to thank Mr Seyed Bagher Mirtajeddini for his beneficial comments and technical discussions.

\section{References}

1 E. L. Ding, S. M. Hutfless, X. Ding and S. Girotra, Chocolate and prevention of cardiovascular disease: a systematic review, Nutr. Metab., 2006, 3(3), 2.

2 G. Maskarinec, Chocolate and Cancer Prevention?, in Chocolate in Health and Nutrition, ed. R. R. Watson, V. R. Preedy and S. Zibadi, London, Humana Press, 2013.

3 B. Holland, A. A. Welch, J. D. Unwin, D. H. Buss and A. A. Paul, McCance and Widdowson's The Composition of Foods, Royal Society of Chemistry, Cambridge, 1991.

4 A. Radowski, Enjoying chocolate needs no sugar, Agro Food Ind. Hi-Tech, 2006, 17, XXIV-XXVI.

5 M. Kroger, K. Meister and R. Kava, Low-calorie sweeteners and other sugar substitutes: a review of the safety issues, Compr. Rev. Food Sci. Food Saf., 2006, 5, 35-47.

6 L. O. Nabors, Alternatives Sweeteners, Marcel Dekker, New York, 2001.

7 R. P. Aidoo, F. Depypere, E. O. Afoakwa and K. Dewettinck, Industrial manufacture of sugar-free chocolates applicability of alternative sweeteners and carbohydrate polymers as raw materials in product development, Trends Food Sci. Technol., 2013, 32, 84-96.

$8 \mathrm{H}$. Rasouli Pirouzian, A. Homayouni Rad and S. B. Mirtajeddini, Polyols in Chocolate Industry, LAMBERT Academic Publishing, 2019.

9 H. Mitchell, Sweeteners and Sugar Alternatives in Food Technology, Blackwell Publishing Ltd, United Kingdom, 2006.

10 P. M. Olinger, New options for sucrose-free chocolate, Manuf. Confect., 1994, 74, 77-84.

11 R. P. Aidoo, E. O. Afoakwa and K. Dewettinck, Rheological properties, melting behaviours and physical quality characteristics of sugar-free chocolates processed using inulin/polydextrose bulking mixtures sweetened with stevia and thaumatin extracts, LWT-Food Sci. Technol., 2015, 62, 592-597.

12 A. B. Shah, G. P. Jones and T. Vasiljevic, Sucrose-free chocolate sweetened with Stevia rebaudiana extract and containing different bulking agents-effects on physicochemical and sensory properties, Int. J. Food Sci. Technol., 2010, 45, 1426-1435.

13 B. M. Azevedo, J. M. Ferreira, V. Luccasand and H. M. Bolini, The influence of the rebaudioside A content of stevia (Stevia rebaudiana Bertoni) on the determination of sweetness equivalence in bittersweet chocolates, using the timeintensity analysis, J. Food Sci., 2016, 81, S3006-S3014. 
14 A. Belščak-Cvitanović, D. Komes, M. Dujmović, S. Karlović, M. Biškić, M. Brnčić and D. Ježek, Physical, bioactive and sensory quality parameters of reduced sugar chocolates formulated with natural sweeteners as sucrose alternatives, Food Chem., 2015, 167, 61-70.

15 H. Rasouli Pirouzian, S. H. Peighambardoust and S. Azadmard Damirchi, Sucrose-free milk chocolate sweetened with different bulking agents: effects on physicochemical and sensory properties, BFAIJ, 2016, 8, 340-349.

16 A. Sokmen and G. Gunes, Influence of some bulk Sweeteners on rheological properties of chocolate, LWT-Food Sci. Technol., 2006, 39, 1053-1058.

17 N. Konar, Influence of conching temperature and some bulk sweeteners on physical and rheological properties of prebiotic milk chocolate containing inulin, Eur. Food Res. Technol., 2013, 236, 135-143.

18 AOAC, Official Methods of Analysis, Association of Official Analytical Chemists, Washington, 15th edn, 1990.

19 ICA, Viscosity of cocoa and chocolate products, Analytical method 46, Bruxelles, Belgium, CAOBISCO, 2000.

$20 \mathrm{H}$. Gloria and D. Sievert, Changes in the physical state of sucrose during dark chocolate processing, J. Agric. Food Chem., 2001, 49, 2433-2436.

21 J. Laličić-Petronijević, J. Popov-Raljić, D. Obradović, Z. Radulović, D. Paunović, M. Petrušić and L. Pezo, Viability of probiotic strains Lactobacillus acidophilus NCFM ${ }^{\circledR}$ and Bifidobacterium lactis HN019 and their impact on sensory and rheological properties of milk and dark chocolates during storage for 180 days, J. Funct. Foods, 2015, 15, 541-550.

22 N. Shadwell, F. Villalobos, M. Kern and M. Y. Hong, Blooming reduces the antioxidant capacity of dark chocolate in rats without lowering its capacity to improve lipid profiles, Nutr. Res., 2013, 33, 414-421.

23 E. O. Afoakwa, Chocolate Science and Technology, Wiley Blackwell, United Kingdom, 2010.

24 E. O. Afoakwa, Chocolate Science and Technology, Wiley Blackwell, United Kingdom, 2nd edn, 2014.

25 R. P. Aidoo, E. O. Afoakwa and K. Dewettinck, Optimization of inulin and polydextrose mixtures as sucrose replacers during sugar-free chocolate manufacture-rheological, microstructure and physical quality characteristics, J. Food Eng., 2014, 126, 35-42.

26 J. B. Hutchings, Food Colour and Appearance, Blackie A \& P, Glasgow, 1994.

27 K. Rossini, C. P. Z. Norena and A. Brandelli, Changes in the colour of white chocolate during storage: potential roles of lipid oxidation and non-enzymatic browning reactions, $J$. Food Sci. Technol., 2011, 48, 305-311.

28 A. D. Saputro, D. V. Walle, S. Kadivar, M. A. Mensah, J. Van Durme and K. Dewettinck, Feasibility of a small-scale production system approach for palm sugar sweetened dark chocolate, Eur. Food Res. Technol., 2017a, 243, 955-967.

29 M. Shourideh, A. Taslimi, M. H. Azizi and M. A. Mohammadifar, Effects of D-Tagatose and inulin on some physicochemical, rheological and sensory properties of dark chocolate, Int. J. Biosci., Biochem. Bioinf., 2012, 2, 314-319.

30 S. T. Beckett, Industrial Chocolate Manufacture and Use, Wiley Blackwell Publication, United Kingdom, 2009.

31 O. S. Toker, F. T. Zorlucan, N. Konar, O. Daglıglu, O. Sagdic and S. Sener, Investigating the effect of production process of ball mill refiner on some physical quality parameters of compound chocolate: response surface methodology approach, Int. J. Food Sci. Technol., 2017, 52, 788-799.

32 P. K. Awua, Cocoa Processing and Chocolate Manufacture in Ghana, David Jamieson and Associates, United Kingdom, 2002.

33 A. D. Saputro, D. V. Walle, R. P. Aidoo, M. A. Mensah, C. Delbaere, N. D. Clercq, J. V. Durme and K. Dewettinck, Quality attributes of dark chocolates formulated with palm sap-based sugar as nutritious and natural alternative sweetener, Eur. Food Res. Technol., 2017b, 243, 177-191.

34 A. D. Saputro, D. Van de Walle, S. Kadivar, M. D. Sintang, P. Van der Meeren and K. Dewettinck, Investigating the rheological, microstructural and textural properties of chocolates sweetened with palm sap-based sugar by partial replacement, Eur. Food Res. Technol., 2017c, 243, 1729-1738.

35 A. D. Saputro, D. Van de Walle, B. A. Caiquoa, M. Hinneha, M. Kluczykoffc and K. Dewettinck, Rheological behaviour and microstructural properties of dark chocolate produced by combination of a ball mill and a liquefier device as small scale chocolate production system, LWT-Food Sci. Technol., 2019, 100, 10-19.

36 C. R. Gomes, F. Z. Vissotto, A. L. Fadini, E. V. Faria and A. M. Luiz, Influence of different bulk agents in the rheological and sensory characteristics of diet and light chocolate, Food Sci. Technol., 2007, 27, 614-623.

37 J. Bouzas and B. D. Brown, in Effects of Food Quality, ed. A. D. Gaonkar, Marcel and Dekker, New York, 1995, p. 451.

38 E. Afoakwa, A. Paterson and M. Fowler, Factors influencing rheological and textural qualities in chocolate - a review, Trends Food Sci. Technol., 2007, 18, 290-298.

39 S. Abbasi and H. Farzanmehr, Optimization of the formulation prebiotic milk chocolate based on rheological properties, Food Technol. Biotechnol., 2009, 47, 396-403.

40 B. Pajin, L. Dokić, D. Zarić, D. Šoronja-Simović, I. Lončarević and I. Nikolić, Crystallization and rheological properties of soya milk chocolate produced in a ball mill, J. Food Eng., 2013, 114, 70-74.

41 L. T. Rodriguez Furlan, Y. Baracco, N. Zaritzky and M. E. Campderrós, Influence of Sucralose and Stevia on the physicochemical properties of free sugar chocolate, Asian J. Sci. Technol., 2016, 7, 3227-3234.

42 B. Schantz and H. Rohm, Influence of lecithin-PGPR blends on the rheological properties of chocolate, LWT-Food Sci. Technol., 2005, 38, 41-45.

43 E. Afoakwa, A. Paterson and M. Fowler, Effects of particle size distribution and composition on rheological properties of dark chocolate, Eur. Food Res. Technol., 2008, 226, 1259-1268.

44 T. A. Stortz and A. G. Marangoni, Heat resistant chocolate, Trends Food Sci. Technol., 2011, 22, 201-214. 
45 V. Briones, J. M. Aguilera and C. Brown, Effect of surface topography on color and gloss of chocolate samples, $J$. Food Eng., 2006, 77, 776-783.

$46 \mathrm{~K}$. Holm, The relations between food structure and sweetness, a literature review, Danisco Sugar $A B$, SIK and the Department of Chemical and Biological Engineering, Chalmers University of Technology, Sweden, 2006.

47 R. Kaushik, N. Pradeep, V. Vamshi, M. Geetha and A. Usha, Nutrient composition of cultivated stevia leaves and the influence of polyphenols and plant pigments on sensory and antioxidant properties of leaf extracts, J. Food Sci. Technol., 2010, 47, 27-33.
48 J. V. Popov-Raljic and J. G. Lalicic-Petronijivic, Sensory properties and colour measurements of dietary chocolates with different compositions during storage for up to 360 days, Senors, 2009, 9, 1996-2016.

49 A. Homayouni Rad, A. Azizi, R. Dargahi, O. Bakhtiari, M. Javadi, M. Jafarzadeh Moghaddam, H. Homayouni Rad, S. B. Mirtajeddini, N. Mobaraki Asl, M. Tayebali and H. Rasouli Pirouzian, Development of synbiotic milk chocolate enriched with Lactobacillus paracasei, Dtagatose and galactooligosaccharide, $A F B, 2018,5,59-68$. 